\title{
A bankable method of assessing the performance of a CPV plant
}

\author{
Jonathan Leloux , Eduardo Lorenzo , Beatriz García-Domingo , Jorge Aguilera , Christian A. Gueymard
}

\author{
H I G H L I G H T S
}

- This methodology allows estimating the long-term energy production of a CPV project with $\sigma=5 \%$.

- The long-term trend of DNI is determined from satellite and its bias is corrected through a measurement campaign.

- The Yield Assessment is carried out using a physical model that simulates the energetic yield of a reference CPV system.

- The Certificate of Provisional Acceptance is delivered through on-site measurements achievable within one or two weeks.

- The Certificate of Final Acceptance is awarded on the basis of a continuous monitoring campaign during 1 or 2 years.

\begin{abstract}
A B S T R A C T
Concentrating Photovoltaics (CPV) is an alternative to flat-plate module photovoltaic (PV) technology. The bankability of CPV projects is an important issue to pave the way toward a swift and sustained growth in this technology. The bankability of a PV plant is generally addressed through the modeling of its energy yield under a baseline loss scenario, followed by an on-site measurement campaign aimed at verifying its energy performance. This paper proposes a procedure for assessing the performance of a CPV project, articulated around four main successive steps: Solar Resource Assessment, Yield Assessment, Certificate of Provisional Acceptance, and Certificate of Final Acceptance. This methodology allows the long-term energy production of a CPV project to be estimated with an associated uncertainty of $\approx 5 \%$. To our knowledge, no such method has been proposed to the CPV industry yet, and this critical situation has hindered or made impossible the completion of several important CPV projects undertaken in the world. The main motive for this proposed method is to bring a practical solution to this urgent problem. This procedure can be operated under a wide range of climatic conditions, and makes it possible to assess the bankability of a CPV plant whose design uses any of the technologies currently available on the market. The method is also compliant with both international standards and local regulations. In consequence, its applicability is both general and international.
\end{abstract}

\section{Introduction}

Concentrating Photovoltaics (CPV) is an alternative to the more classic photovoltaic (PV) technology based on flat-plate modules. From 2008 to 2013, the price of conventional crystalline silicon (xSi) PV modules has decreased sharply from $€ 3.5 / \mathrm{W}$ to $€ 0.5 / \mathrm{W}$, a sevenfold decrease [1]. The challenge for CPV being to compete mainly with PV has therefore grown in similar proportions. Economies of scale represent the key factor that has been chiefly responsible for driving down the prices of $\mathrm{xSi}$ modules, which benefitted from a learning curve that allowed costs to be reduced by $20 \%$ for each doubling of the manufacturing capacities [2].
CPV technologies will have to follow a steeper learning curve [3] to have a chance of becoming commercially viable in the long term. Still, to date, very few CPV installations have been commissioned worldwide relative to conventional PV, and the initiatives are being taken by a reduced number of technology leaders [4]. The sector thus needs a quick and consequent kick-start if it is ever to validate this steeper learning curve and become part of the future energy scenario [5-7]. The bankability of CPV installations is an important issue in paving the way to a swift and sustained growth in this technology [8], but several significant obstacles still remain. Little detailed operational data relevant to CPV installations has been published to date [9-12]. A first International Electrotechnical Commission (IEC) standard for CPV modules has been under way for several years [13-19], but it is unlikely that a broader standard will be developed soon to provide guidance on evaluating the bankability of CPV plants. Therefore a robust methodology is 
rapidly needed to accelerate the financing of new CPV plants, a methodology that is both sufficiently accurate to be accepted by the CPV industry as well as by financial entities, and sufficiently simple and versatile to be of a practical application during the whole project assessment process, while using as little technical information as possible. At this point it is important to emphasize the current absence of any established procedure that could be used to assess the financial viability of a CPV project.

The bankability of a conventional PV plant is generally addressed through the modeling of its energetic yield under a baseline loss scenario, followed by an on-site measurement campaign. These two steps are compulsory when project finance is requested from a financial entity, for which it is critical to make sure that the energetic yield will be high enough to ensure the expected financial return. The assessment procedure must therefore be defined in a way that must be rigorous from a scientific point of view, and at the same time discriminant enough to result in clear PV plant acceptance/rejection decisions. In the case of conventional PV plants, the solution is relatively straightforward, because the DC power output of the PV generator is properly described by [25]:

$P_{D C}=P^{*} \frac{G}{G^{*}}\left[1+\gamma\left(T_{C}-T_{C}^{*}\right)\right] \cdot\left[1+C \ln \frac{G}{G^{*}}\right] f_{D C}$

where the symbol ${ }^{*}$ refers to Standard Test Conditions (STC), $P_{D C}$ is the DC power output of the PV generator, $P^{*}$ is the nameplate DC power of the PV generator, $G$ is the global (plane-of-array) solar irradiance received by the PV generator, $G^{*}$ is the global solar irradiance under STC, $\gamma$ is the coefficient of power variation due to cell temperature, $T_{c}$ and $T_{c}^{*}$ are respectively the cell temperatures under operating and STC conditions, $C$ is the variation coefficient of current with solar irradiance, and $f_{D C}$ is a coefficient that lumps together all the additional system losses in DC, e.g., technology-related issues, soiling and shading.

The corresponding $\mathrm{AC}$ power output is then given by:

$P_{A C}=P_{D C} \eta_{I N V} f_{A C}$

where $P_{A C}$ is the AC power output of the PV generator, $\eta_{I N V}$ is the yield of the inverter (which can be estimated from several coefficients characteristic of its load curve), and $f_{A C}$ is a coefficient that lumps together all the technology-related additional AC system losses. by:

The energy produced during a period of time $T$ is finally given

$E_{A C}=\int_{T} P_{A C} d t$

As a matter of fact, these procedures are already being implemented in the current PV market for large PV plants (say, larger than $1 \mathrm{MW}$ ), and rely on available and trustworthy solar engineering simulation software, solar radiation databases, and widely accepted performance figures, such as the Performance Ratio (PR). All this solid information is a guarantee of relatively low uncertainties along the process.

The main difference between PV and CPV resides in the CPV modules themselves, in particular in the inclusion of optical elements and III-V multijunction cells that are much more sensitive to the variations of the spectral direct solar irradiance than XSi cells [20], while the rest of the system behaves in a way that possesses many common points with xSi technology. The modeling of the DC power output of a CPV system thus requires several important second-order parameters to be considered, mainly related to optics, spectral direct irradiance, wind speed, tracker accuracy and heat dissipation of cells. The relation between DC power output and operational conditions thus takes the general form:
$P_{D C}=P^{*} \frac{D N I}{D N I^{*}} f_{S H A D} f_{S O I I} f_{\lambda} f_{T E M P} f_{D C}$

where DNI stands for Direct Normal Irradiance, and the power losses coefficients $f_{S H A D}, f_{\text {SOIL }}, f_{\lambda}, f_{\text {TEMP }}$ and $f_{D C}$ are related, respectively to shading, soiling, spectral distribution of DNI, cell temperature and technology-related issues, i.e., differences between real and nominal characteristics of the PV system.

Apart from the potential complexity of the physical models involved behind each one of these losses parameters, the practical use of this equation is made difficult by the necessity of their experimental verification during an on-field campaign [21]. For example, during on-site measurement campaigns of conventional PV plants, the second-order effects of temperature, solar spectrum and soiling are offset by the measurement of the solar irradiance and cell temperature by means of reference PV modules of a technology that is similar to the one of the modules installed (similar spectral response, similar power temperature coefficient) and of a similar degree of soiling. However, when CPV is concerned, these second-order effects are much more significant, and additional sources of power losses, such as the tracker accuracy, make the use of calibrated CPV modules virtually impossible. As a consequence, the CPV industry now necessitates quality control procedures that are adapted to the CPV technological specificities: spectral direct beam irradiance (instead of broadband global irradiance), high spectral sensitivity of solar cells and optics, high dependence of power output to tracking accuracy, etc. Improper consideration of these peculiarities typically translates into important uncertainties that are unacceptable from the investor's point of view, and which indeed have recently hindered or made impossible the completion of several important world CPV projects $[22,23]$. The practical experience is still too scarce to model the losses related to field conditions or technology-related issues with a sufficient degree of accuracy for bankability. Meanwhile, some early CPV projects of importance have revealed productivities well below expectations, indicating that too optimistic assumptions can lead to unpleasant situations. An illustrative example is the case of the then largest CPV plant in the world, installed in 2007 in Spain, in which the energy productivity from 2009 to 2012 was $30 \%$ below expectations [24]. At the beginning of 2013, the owners of the plant finally took the decision to replace all the CPV modules with XSi modules at their own cost, because it still made more economical sense to them. The CPV industry cannot afford to multiply these harmful experiences, which would wipe out its credit among investors.

During the last five years, the Universidad Politécnica de Madrid (UPM) and Universidad Politécnica de Jaén (UJAEN) have offered both indoor and outdoor control quality services to the PV and $\mathrm{CPV}$ industry, and have carried out on-site quality control campaigns for more than $60 \mathrm{PV}$ plants totaling more than $300 \mathrm{MW}$, in close relation with Engineering, Procurement and Construction Contractors (EPCC) and financial entities. The experience thus gained has been published elsewhere [25-32]. Both universities have also been taking extensive meteorological measurements at their facilities in Madrid [33] and Jaén [34].

A growing number of models are now published in the literature to deal with specific parts of a CPV system, but these publications belong to a wide variety of disciplines, and are usually understood by completely different categories of experts. The present contribution presents a selection of applicable modeling methods with the aim of reaching a compromise between accuracy and simplicity, in a language as understandable as possible by the industry [35]. It summarizes the authors' previous experiences with assessing the performance of conventional PV plants in commercial frameworks and testing industrial CPV prototypes. To the best of our knowledge, the proper consideration of such peculiarities (a 
bankable method of assessing the performance of a CPV plant that can be used by investors in practice and can lower uncertainties) has never been proposed before. This is the main justification for this contribution, whose most important novelties are twofold: (i) the establishment of a simple and practical method to assess the direct irradiance resource with low uncertainty; and (ii) the establishment of a practical procedure for the field assessment of the energetic yield of large commercial grid-connected CPV systems, based on just a few days of operation.

With this procedure, a bankable assessment of a CPV plant (which can use any kind of technology currently available on the market) may be undertaken, and operated under the whole range of climatic conditions that are suitable for its deployment. The procedure is designed to be fully compliant with international standards and to be easily merged with local regulations. In consequence, its applicability is both general and international.

\section{Methodology overview}

To estimate the financial attractiveness of a project, investors must evaluate two important characteristics: projected profitability and risk. The projected profitability is represented by the parameter $E_{P 50}$, which is the estimated most probable value of the annual energy production. Under the assumption that the differences between estimates and true values respect a Gaussian probability distribution, it is possible to estimate the risk from the standard uncertainty $u$ that affects the energy production [36]. Projected profitability and risk are then usually lumped together through the concept of $E_{P 90}$ (the value of the energy production below which the real production has only a $10 \%$ probability of occurring), defined as:

$E_{P 90}=E_{P 50}-1.28 u$

Fig. 1 illustrates the relationship between $E_{P 50}, E_{P 90}$ and $u$. Although $E_{P 90}$ is the statistic used by most financial institutions, some are more conservative and may rather use $E_{P 95}$ or even $E_{P 99}$. In such cases the coefficient 1.28 would change accordingly, to 1.96 and 2.58 , respectively, by application of the properties of Gaussian distributions. The rest of the methodology developed here would be applicable without additional modifications.

The $E_{P 90}$ approach alone is not able to assess certain kinds of risks whose probability of occurrence or magnitude does not follow a Gaussian distribution. This is the case of some events characterized by both a very low probability of occurrence and a high impact in case of occurrence, e.g., major natural disasters. This is also the case with the risks related to the compliance to mandatory international standards or local regulations, which do not show up during the analysis of the performance of the CPV plant, but which can bear critical consequences on the economic viability of the project. Some of these risks can be minimized through due diligence, both at technical and legal levels, during several critical steps of the project, and before any in-depth performance analysis is undertaken. Some other risks are better mitigated through insurance policy. The next

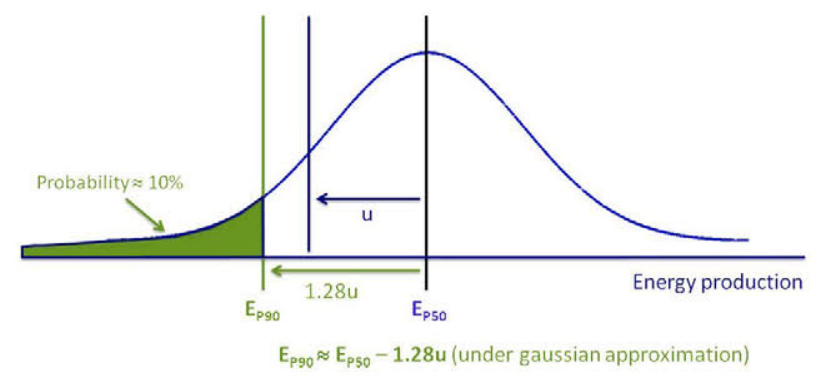

Fig. 1. Relationship between the estimated energy production and its uncertainty. sections describe how to minimize and mitigate these risks alongside with the $E_{P 90}$ performance assessment.

The assessment of $E_{P 50}$ is achieved through four successive steps: Solar Resource Assessment (SRA), Yield Assessment (YA), Certificate of Provisional Acceptance (CPA), and Certificate of Final Acceptance (CFA).

The Solar Resource Assessment for CPV projects aims at evaluating the long-term solar resource that is available at the location where the CPV plant is projected, as well as its temporal variability. It requires an assessment of DNI, both at broadband and spectral levels, as well as air temperature and wind speed.

The Yield Assessment is carried out before the construction of the project using a physical model (detailed later in this report), which is used to simulate the energetic yield of a reference CPV system. Its technical characteristics are extracted directly from the technical information supplied by the EPCC. This means that the system's performance is assumed to be optimal, and that all its components are assumed to correspond exactly to the technical datasheets of the manufacturers. After estimating the energy produced by the reference CPV system, all the parties involved in the project (EPCC, investors and independent experts) agree on a baseline loss scenario. This establishes the maximum allowable difference between the performance of the reference CPV system and the real system to be constructed. This allowable difference represents a margin of safety and is quantified by a target Performance Index [37,38] $\left(\right.$ PI $\left._{\text {TARGET }}\right)$, which is the ratio between the energy production of the CPV system under the baseline loss scenario $\left(E_{B A S E L I N E}\right)$ during a certain period, and the corresponding energy production of the reference CPV system $\left(E_{R E F}\right)$ :

$P I_{\text {TARGET }}=\frac{E_{\text {BASELINE }}}{E_{\text {REF }}}$

The Certificate of Provisional Acceptance is delivered on the basis of on-site measurements of the energy production $\left(E_{M E A S}\right)$ that are generally taken just after the commissioning of the CPV project, and whose duration is typically of one or two weeks under clearsky conditions. Acceptance requires the satisfaction of:

$E_{\text {MEAS }} \geqslant E_{R E F} \times P I_{\text {TARGET }}$

Finally, the Certificate of Final Acceptance is awarded on the basis of a continuous monitoring campaign that takes place at the CPV plant 1 or 2 years after its commissioning. The CFA verifies the quality of the operation and maintenance, and looks for hidden defects or second-order causes of energy losses that were not possible to assess during the CPA step (such as soiling or aging of the CPV modules).

All this considered, the global uncertainty on the estimation of $E_{P 50}$ of a CPV project can be mathematically expressed from the uncertainties attached to the four successive steps (SRA, YA, CPA and CFA), as [39]:

$u=\sqrt{u_{S R A}^{2}+u_{Y A}^{2}+u_{C P A \mid C F A}^{2}}$

where

$u_{C P A \mid C F A}=\operatorname{MIN}\left(u_{C P A}, u_{C F A}\right)$

Because the uncertainties are conventionally considered independent and hence added using the square law, the global uncertainty is led by the highest source of uncertainty among the three components. A reduction of uncertainty in the two other components well beyond the largest one is therefore of little practical significance, and actually represents an undesired added complexity. Our methodology thus aims at achieving a good balance between the three sources of uncertainty, by minimizing the overall uncertainty as much as possible while keeping the process as simple as possible, and by allowing the performance of a 
CPV project to be assessed with an associated uncertainty that is typically $\approx 3 \%$ for each of the three components. Under such favorable conditions, the resulting overall uncertainty for the long-term energy production of the CPV project of $\approx 5 \%$, which leads to $E_{P 90}$ being typically $6.5 \%$ lower than $E_{P 50}$.

\section{Solar Resource Assessment (SRA)}

The energy produced by CPV modules is mainly determined by their incident broadband DNI, modulated by its spectral distribution. Among other things, the SRA step must therefore assess the long-term trend in DNI, i.e., over several decades, as well as its spectral content associated with any particular operating condition. Air temperature and wind speed need also be assessed. Air temperature affects the energetic behavior of the CPV modules and the concentrating properties of their optical elements. Most CPV modules must track the Sun with enough accuracy that the optics can perform its concentrating role properly. Wind speed influences negatively the accuracy of the tracker itself, while exerting a positive cooling effect on the CPV modules.

The long-term trend in DNI during the past decades is determined from satellite-derived modeled data or ground observations [40-42], using a time series of ideally more than 10 years. The availability of long-term DNI datasets is far lower than for Global Horizontal Irradiance (GHI). Nevertheless, DNI can be estimated from GHI using an empirical decomposition model [43-46]. Both the broadband and spectral DNI can be simulated using a high-resolution clear-sky radiative transfer model, such as SMARTS [47]. This estimation of the solar resource for CPV from the combination of long-term datasets and SMARTS is relatively straightforward, at least in principle, since it can be carried out with a limited amount of information. In practice, however, this procedure can generate errors of more than $30 \%$ during the estimation of the annual broadband DNI, due to several drawbacks already detailed in previous studies. First, DNI datasets can contain biased values [48]. Second, the aerosol-induced variability in DNI is typically 2-4 higher than that in GHI [49]. Third, the spectral distribution of DNI is relatively sensitive to temporal variations or estimation errors in some atmospheric components, in particular aerosols and water vapor. Fourth, an Aerosol Optical Depth (AOD) database [50] of sufficient quality and high spatial resolution for worldwide accurate DNI prediction is still not available [51]. Fifth, spectral DNI measurements taken by a spectroradiometer are scarce, costly and elaborate. Here, we propose an approach that addresses these challenges with minimal complexity.

Before the construction of the CPV project, a ground-measurement campaign of at least 1 year needs to be carried out, using an appropriate weather station. It must be sited and maintained properly to accurately monitor $\mathrm{DNI}, \mathrm{GHI}$, air temperature, and wind speed with a 10 -min temporal resolution or better. It is mandatory that these measurements be obtained and their uncertainties calculated strictly in accordance with all relevant international standards or guidelines $[35,52]$.

Any possible bias in the long-term modeled DNI time series can then be corrected by optimally using the shorter-term values obtained during the on-site measurement campaign. This bias is corrected retroactively, using one of various, and more or less sophisticated, statistical methods $[45,53,54]$. Based on recent evidence $[46,49]$, our proposed methodology assumes that the main source of bias in the modeled DNI is the aerosol content of the atmosphere (characterized by its AOD), which varies seasonally [55]. Our calculations are thus undertaken on a monthly basis, and start with the estimation of monthly biases:

$\delta_{m}=\frac{D N I_{m, D B}}{D N I_{m, M E A S}}$ where $m$ is the month of the year from 1 to $12, D N I_{m, M E A S}$ is the monthly value of DNI measured by the in situ radiometer, $D N I_{m, D B}$ is the corresponding modeled value provided by the database, and $\delta_{m}$ is the bias between modeled and measured data. The estimated biases are then applied to correct the long-term data:

$D N I_{m, L T, \varepsilon}=\frac{D N I_{m, L T, D B}}{\delta_{m}}$

where $D N I_{m, L T, D B}$ is the long-term value of DNI contained in the database and $D N I_{m, L T, \varepsilon}$ is the corresponding value corrected by the present method. Table 1 applies this operation using the DNI measured in Jaén, Spain, from August 2011 to July 2012, to correct the bias of the DNI values obtained from the application of a solar radiation decomposition model to the GHI values acquired from the SoDa [ 40$]$ database. The annual bias there is $\approx 4 \%$, which is relatively low compared to other sites, with seasonal variations up to $6 \%$. The SoDa database offers modeled DNI values limited to the period 2004 to 2011 in this case. Our estimation of the most representative annual DNI long-term value yields $2131 \mathrm{~kW} / \mathrm{m}^{2}$. Note that at some locations, monthly AOD shows a large interannual variability. In this case, the correction of the monthly bias would necessitate a more involved procedure, although the underlying methodology remains unchanged.

The interannual variability in AOD directly translates into interannual variability in DNI [47], which in turn entails a higher volatility of annual cash flows. Fortunately, this variability in AOD is found generally low over most of the regions of the world that are suitable for the installation of CPV plants, resulting in normally low interannual DNI variability, typically within $5 \%$ from the long-term average DNI, and therefore 2-4 times less in GHI. As an example, IES-UPM recently carried out an SRA in the context of a PV project located near Calama, in the region of Antofagasta, northern Chile (Latitude $=22.233^{\circ} \mathrm{S}$; Longitude $=69.578^{\circ} \mathrm{W}$; Altitude $=1168 \mathrm{~m}$ ). Long-term solar resource data for this region are scarcely available. Fortunately, collaboration between the Chilean Energy Ministry (CNE) and the German Cooperation Agency (GIZ) led to the installation of several meteorological stations in this region, starting in 2008. These stations are very well equipped and carefully maintained, and they provide high-quality data. All recorded data are freely available from the website of Red de Energía Solar Fotovoltaica de Latinoamérica y el Caribe [56]. One of these stations, named Crucero, is very close to the projected PV plant, and provides daily GHI (but no DNI) data from September 2009, as shown in Table 2 . After 4 years of measurements, the mean daily GHI for this location amounts to $7108 \mathrm{Wh} / \mathrm{m}^{2}$, which represents a very attractive solar resource. Furthermore, the temporal variation of GHI is remarkably low. This is typical of very dry (therefore very clear) atmospheres, and of arid climates, which are scarcely affected by the randomness associated with cloudiness. Variations in yearly and monthly GHI from their mean value are typically lower than $1 \%$ and $5 \%$, respectively. The DNI variability should be represented by numbers that are $2-4$ times larger. Exceptions to the low interannual variability in DNI would typically occur over arid or desert regions that are occasionally or regularly impacted by dust storms [47].

Regarding spectral DNI, SMARTS yields the same degree of accuracy than the on-site measurements carried out by spectroradiometers [57], if provided with inputs of sufficient accuracy. The most sensitive ones are precipitable water (PW), which SMARTS can estimate from local measurements of Relative Humidity and air temperature if no better PW data are available, and AOD, which is modeled through the use of two Angström turbidity coefficients, $\alpha$ and $\beta$ [58]. Physically, $\beta$ is the AOD at $1 \mu \mathrm{m}$, and represents the optical load of aerosols present in the atmosphere, while the value of $\alpha$ is inversely related to their average size. The most typical value of $\alpha$ is 1.3 , corresponding to a rural or continental aerosol size 
Table 1

Correction of the bias in DNI from the SoDa long-term database by comparison with 1-year measurements in Jaén, Spain.

\begin{tabular}{|c|c|c|c|c|c|c|c|c|c|c|c|c|c|}
\hline & January & February & March & April & May & June & July & August & September & October & November & December & Year \\
\hline $\begin{array}{l}\text { DNI short-term database } \\
\left(\mathrm{kW} \mathrm{h} / \mathrm{m}^{2}\right) \text { (SoDa } \\
\text { August 2011-July } \\
\text { 2012) }\end{array}$ & 111.6 & 103.6 & 137.6 & 163.1 & 175.2 & 233.1 & 275.6 & 284.3 & 269.4 & 243.5 & 201.5 & 128.8 & 2327.2 \\
\hline 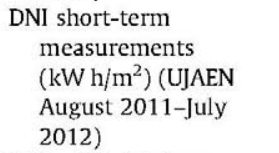 & 109.7 & 103.0 & 131.0 & 156.7 & 166.6 & 220.9 & 258.3 & 270.6 & 258.9 & 236.2 & 199.7 & 126.2 & 2237.8 \\
\hline $\begin{array}{l}\text { Delta DNI database- } \\
\text { measurements (\%) }\end{array}$ & 1.70 & 0.60 & 4.80 & 3.90 & 4.90 & 5.20 & 6.30 & 4.80 & 3.90 & 3.00 & 0.90 & 2.00 & 3.84 \\
\hline $\begin{array}{l}\text { DNI long-term database } \\
\left(\mathrm{kW} \mathrm{h} / \mathrm{m}^{2}\right)(\text { SoDa } \\
2004-2011)\end{array}$ & 122.5 & 133.8 & 183.3 & 192.3 & 223.5 & 242.8 & 279.4 & 240.7 & 210.1 & 158.1 & 116.3 & 113.3 & 2216.3 \\
\hline $\begin{array}{l}\text { DNI long-term } \\
\text { estimation }\left(\mathrm{kW} \mathrm{h} / \mathrm{m}^{2}\right) \\
\text { (corrected by present } \\
\text { method) }\end{array}$ & 116.7 & 128.6 & 177.8 & 190.6 & 219.0 & 238.7 & 277.7 & 229.1 & 201.9 & 150.4 & 110.3 & 106.2 & 2131.1 \\
\hline
\end{tabular}

Table 2

Mean daily GHI observed at the meteorological station of Crucero, Antofagasta, Chile, from 2009 to 2012.

\begin{tabular}{|c|c|c|c|c|c|}
\hline & \multirow[t]{2}{*}{ Mean daily $\mathrm{GHI}\left(\mathrm{Wh} / \mathrm{m}^{2}\right)$} & \multicolumn{4}{|c|}{ Variation in $\mathrm{GHI}$ relative to average (\%) } \\
\hline & & 2009 & 2010 & 2011 & 2012 \\
\hline January & 8826 & & 0.6 & 1.1 & -1.7 \\
\hline February & 7778 & & 5.6 & -0.5 & -5.1 \\
\hline March & 7636 & & 0.9 & 1.5 & -2.4 \\
\hline April & 5859 & & -12.0 & 9.8 & 2.2 \\
\hline May & 5255 & & -2.3 & 0.9 & 1.4 \\
\hline June & 4720 & & 0.8 & -2.3 & 1.5 \\
\hline July & 5061 & & 4.0 & -2.6 & -1.4 \\
\hline August & 6164 & & 0.8 & -0.4 & -0.4 \\
\hline September & 7346 & -0.8 & 0.6 & 1.2 & -1.0 \\
\hline October & 8445 & -0.1 & 0.5 & -0.7 & 0.3 \\
\hline November & 9068 & -2.5 & 1.5 & 0.2 & 0.8 \\
\hline December & 9081 & 0.0 & 2.3 & -2.9 & 0.6 \\
\hline Year & 7108 & N.A. & 0.5 & 0.4 & -0.5 \\
\hline
\end{tabular}

distribution. We recommend this value by default because it is also the value assumed in various atmospheric standards [59]. Otherwise, a value of $\alpha=0.5$ is typical of aerosols of maritime, desert or volcanic origin, and a higher value, up to $\approx 2.5$, can be found in either pristine/remote or polluted/urban environments. The value of $\beta$ can be estimated from the ratio between the direct and diffuse components of solar radiation, as detailed in others studies $[60,61]$. As an example, Fig. 2 shows the comparison between the spectral DNI measured by a Licor spectroradiometer in Madrid on July 8th, 2011, at 1 PM local civil time, and the corresponding simulation using SMARTS. In this case, the DNI value measured by the pyrheliometer was $759 \mathrm{~W} / \mathrm{m}^{2}$, from which $\beta$ was estimated to be $0.089-$ a value considered typical for Madrid by other authors [62]-and $\alpha$ was set to its default value of 1.3. In the same way, SMARTS can predict very accurate spectral DNI series for any location in the world, as long as it is provided with accurate AOD and PW inputs data. In practice, however, obtaining highly accurate AOD data for any specific location and moment is the main challenge.

The method described above should lead to an uncertainty in the estimation of the long-term mean annual solar resource of $\approx 3 \%$, under the assumptions that (i) no major climatic event impacts the atmospheric aerosol content, such as after the eruptions of El Chichón in 1982 and Pinatubo in 1991; and that (ii) no longterm trends, resulting from e.g., climate change, climatic geoengineering, or large-scale pollution abatements, produce enduring evolutions [63]. Nevertheless, these possibilities must not be

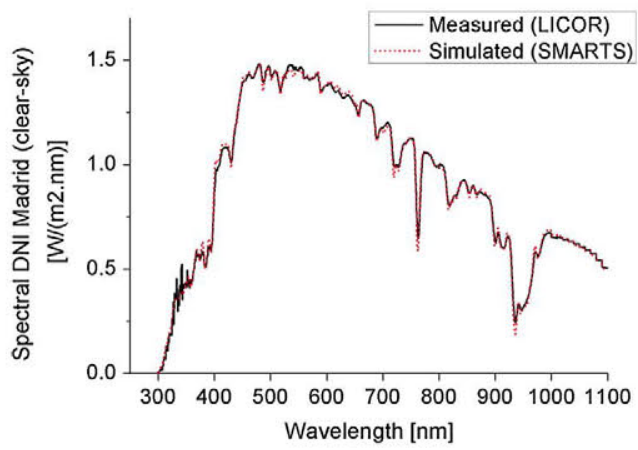

Fig. 2. Comparison of the clear-sky spectral DNI in Madrid on July 8th, 2011, at 1 PM local civil time, measured by a spectroradiometer and simulated using SMARTS.

overlooked when assessing financial risks because their occurrence may have profound implications. Any long-term trend in AOD automatically induces a drift of opposite sign in the mean annual value of DNI [64]. The induced effect on DNI of a major volcanic eruption could represent an increase of $10-30 \%$ in its interannual variability and a drop of $20-30 \%$ in its annual mean value [46]. Whereas an increase in the interannual variability of DNI mostly impacts the cash flows of the CPV project, a decrease of its mean value induces a net loss of financial return. Theoretically, it is 
mathematically possible to estimate the contribution of both sources of uncertainties to the overall uncertainty in the estimation of the solar resource $[65,66]$. Nevertheless, the likelihood of these events is unknown, and the quantification of their impact is a very hazardous enterprise. This is because the existing satellite-derived solar resource datasets are generally post-Pinatubo era only, and the most relevant effects of climate change have still not been observed. Therefore, we recommend handling these additional sources of uncertainties by their inclusion into an insurance policy against excessive losses of energy production, in the same way that these insurance policies already cover against natural disasters, fire, theft, vandalism or political unrest.

\section{Yield Assessment (YA)}

At this stage, the EPCC provides all the necessary technical information related to the CPV plant in project, by extracting it from the datasheets provided by the manufacturers of the components, the construction project plans, the documentation showing compliance with both the international standards and the local regulations that are applicable, etc. Previous studies performed over hundreds of PV projects worldwide have demonstrated that in dynamic, fast changing and complex markets such as CPV, detailed due diligences aimed at reducing the technical and financial risks are especially important [67]. Before assessing the expected yield of the CPV plant, this due diligence must therefore return a positive outcome.

The Yield Assessment is carried out using a physical model to simulate the energetic yield of a reference CPV system, whose technical characteristics are extracted directly from the technical information supplied by the EPCC. Its performance is therefore assumed to be optimal, and all its components are assumed to correspond exactly to the technical datasheets of the manufacturers. Then, since the real CPV plant will generally not perform as well as the reference CPV system, a margin of safety is provided by establishing a PI that is inferior to unity. That PI is used as a realistic target $\left(P I_{\text {TARGET }}\right)$.

The power output of the reference CPV system can be modeled by considering the simultaneous effect of four factors of influence on its nominal power under STC $\left(P^{*}\right)$ :

$P_{\text {REF }}=P^{*} f_{D N I} f_{T E M P} f_{\lambda} f_{S H A D}$

These four factors represent the influence of DNI variations $\left(f_{D N I}\right)$, cell temperature $\left(f_{\text {TEMP }}\right)$, spectral variations $\left(f_{\lambda}\right)$ and shading $\left(f_{S H A D}\right)$.

The correction factor for DNI $\left(f_{D N I}\right)$ is defined as:

$f_{D N I}=\frac{D N I_{M E A S}}{D N I^{*}}$

where $D N I_{M E A S}$ is the actual DNI measured on-site. The $D N I^{*}$ value under which CPV modules are rated is here taken as $900 \mathrm{~W} / \mathrm{m}^{2}$, but this value is currently subject to debate, and could therefore change in the future (to e.g., 850 or 1000 ) [13]. Strictly speaking, the evolution of power output with DNI is not linear because the angular size of the solar disk varies slightly on a seasonal basis (and at sunrise/sunset), but the approximation is correct when $\mathrm{DNI}>600 \mathrm{~W}^{2}$, which leads to good results for the purpose of annual energy calculations [64].

The correction factor for cell temperature $\left(f_{\text {TEMP }}\right)$ is defined as:

$f_{\text {TEMP }}=1+\gamma\left(T_{c}-T_{c}^{*}\right)$

where $\gamma$ is the coefficient of variation of power with temperature, which depends mainly on cell technology and concentration ratio [68]. As a default value, we suggest $\gamma=-0.04 \% / \mathrm{K} . T_{c}$ is still unknown when the Yield Assessment is performed, and must therefore be evaluated from other sources of information [69]. We propose to take advantage of the very good availability of historical databases for air temperature, $T_{a}$, and to correlate $T_{c}$ and $T_{a}$ through an equation derived from Newton's heat equation [20]:

$T_{c}=T_{a}+\frac{D N I \times \eta_{o p t} \times 0.75}{\mu}+5$

where $\eta_{\text {opt }}$ is the efficiency of the optics, which determines the fraction of DNI that reaches the cell. A value of $80 \%$ is typical of the state-of-the-art CPV optics [70]. The 0.75 factor derives from the fact that in practice, about $25 \%$ of the heat is dissipated through the front and side faces of the CPV module, and therefore this fraction of solar irradiance received by the CPV collector does not contribute to the heat exchange between the back plate and the air interface [20]. The parameter $\mu$ is mainly a function of the coolant, of the exchange surface, and of the wind speed $\left(W_{s}\right)$. For practical purposes, we can establish that $\mu=\mu_{0}=5 \mathrm{Wm}^{-2} \mathrm{~K}^{-1}$ for natural convection from a plate to air, and $\mu=30 \mathrm{Wm}^{-2} \mathrm{~K}^{-1}$ when $W_{s}=10 \mathrm{~m} / \mathrm{s}$. We suggest using the following equation between $\mu$ and $W_{s}$ :

$\mu=\mu_{0}+2.5 \times W_{s}$

The significant variation of $\mu$ with wind speed is attenuated at the cell level by the influence of air temperature and by the thermal resistance between back plate and cell. In Eq. (15), the constant factor of $5 \mathrm{~K}$ is suggested as a typical value representing the temperature drop between the cell and back plate. For $W_{s}$ greater than $10 \mathrm{~m} / \mathrm{s}$, our experience is that it is very difficult to rate the power of a CPV system, mainly because air turbulence adds much complexity to the laws of heat exchange, and leads to tracker inaccuracies [71]. Nevertheless, as will be discussed later, these limitations are not relevant when estimating the annual energy produced by a CPV system.

The multijunction III-V cells that equip the vast majority of CPV systems are very sensitive to variations in the spectral distribution of DNI [72-75]. UPM has been measuring spectral DNI on a 30-min temporal resolution since early 2009 using a Licor spectroradiometer. These measurements were used to develop a simple model capable of estimating the energy losses resulting from the current mismatch in the multijunction III-V cells that make up the CPV systems [32,76-78]. From this experience, we propose a simple method for estimating spectral losses. Recent developments in multijunction III-V cells show that the cells composed of more than three subcells will probably play an important role in the future of the CPV market $[79,80]$. Therefore, we here describe a universal method that is valid for $n$ junctions.

First, the spectral DNI, or $D N I(\lambda)$, is simulated using SMARTS, as already explained above. Then, the photocurrent density at the cell is evaluated:

$J_{S C, i}=\int T(\lambda) S R_{i}(\lambda) D N I(\lambda) d \lambda$

where $T(\lambda)$ is the spectral transmittance of the optics of the CPV module, $S R_{i}(\lambda)$ is the spectral response of the subcell $i$, and $J_{S C, i}$ is its photocurrent density, related to the component subcell $i$ of the multijunction cell. Given that the $n$ subcells are connected in series, the photocurrent density achievable at the multijunction cell is given by:

$J_{S C}=\operatorname{MIN}\left(J_{S C, i}\right)$

The maximum power density extractible $\left(P_{E X T R}\right)$ from the multijunction cell without any current mismatch is:

$P_{\text {EXTR }}=\sum_{i=1}^{n} J_{S C, i} \times V_{O C, i}$

where $V_{o c, i}$ can be estimated from: 
$V_{O C, i}=V_{O C, i}^{*} \times \ln \left(\frac{J_{S C, i}}{J_{S C, i}^{*}}\right)$

The correction factor resulting from the variation in DNI's spectral distribution can thus be evaluated by:

$f_{\lambda}=\frac{J_{S C} / J_{S C}^{*}}{P_{E X T R} / P_{E X T R}^{*}}$

The geometrical shading factor $\left(F_{S H A D}\right)$ can be modeled through a 3D simulation [81] and is defined by the ratio of the generator's surface affected by shading $\left(S_{\text {SHAD }}\right)$ to its total surface $(S)$. Since CPV modules are equipped with by-pass diodes between their cells, the impact of shading on power losses is nearly proportional to $F_{S H A D}$, and the correction factor for shading is then obtainable by comparing the power that the CPV system would produce without any shading with the power that it generates considering the actual shading:

$f_{\text {SHAD }}=\frac{P_{\text {WithShading }}}{P_{\text {Withouthhading }}}=1-F_{\text {SHAD }}=1-\frac{S_{\text {SHAD }}}{S}$

In practice, most CPV systems will perform below the yield of the reference system, because additional losses are present in the real world. This translates into the presence of the losses factors $f_{D C}<1$ and $f_{\text {SOIL }}<1$ in the modeling of a real CPV system (Eq. (4)), while these factors are absent from the modeling of the reference CPV system (Eq. (12)). Additionally, several second-order effects generally add to the uncertainty in the yield estimation exercise. It is therefore advisable to consider a margin of safety between the yield of the reference system and that of the real system, by establishing a PI value that is less than unity, and that is used as a realistic target $\left(P I_{\text {TARGET }}\right)$. The main sources of additional losses to be accounted for in PI are as follows: CPV module power default, CPV module soiling, current and voltage mismatch in the DC generators, DC and AC wiring losses, tracking errors or inaccuracies, inverter losses greater than in the reference system, unavailability or failures, low efficiencies at low solar irradiance, and low optical efficiencies at low temperature.

The value of $P I_{\text {TARGET }}$ needs to be agreed upon between the main parties involved in the project, i.e., investors, EPCC and independent technical experts. The greater the margin of safety, the easier it is for the CPV plant to meet its expectations, but the lower the project's value is, and thus, ultimately, the lower the money amount offered by the investor. The margin of safety is therefore the result of a compromise that largely depends on the confidence of the EPCC in its own project, and on the uncertainties linked to the whole assessment process. From our experience, we recommend considering $P I_{\text {TARGET }}=90 \%$ as a good compromise in the majority of cases [25].

Fig. 3 shows a comparison between the targeted power and the measured power for a CPV module installed at UJAEN, under clearsky conditions ( $\mathrm{DNI}>600 \mathrm{~W} / \mathrm{m}^{2}$ ), and for the entire month of July 2011. In this case, the power is measured in DC, and there is no Balance Of System (BOS). The relatively good quality of the linear fit suggests that the use of more complex models to simulate the energy behavior of the CPV module would not be justified for this exercise, because the added complexity would not translate into any substantial improvement in accuracy. The validation of the model for the rest of the system has already been published elsewhere $[25,26]$.

\section{Certificate of Provisional Acceptance (CPA)}

The experience accumulated in the PV sector shows that, before measuring the performance of a PV plant, it is necessary to verify that the project has been properly executed [62]. Therefore, in a

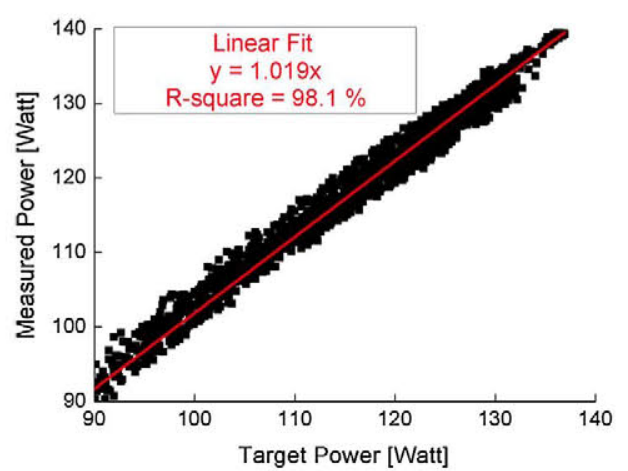

Fig. 3. Comparison between target power and measured power for a CPV module installed at UJAEN, under clear-sky conditions $\left(D N I>600 \mathrm{~W} / \mathrm{m}^{2}\right)$ and for the month of July 2011.

first step, a commissioning procedure is undertaken that aims at verifying the proper installation and functioning of the CPV plant. This includes visual inspection, electrical and thermographic measurements, verification of the completeness and consistency of the as-built documentation, and compliance with local regulations.

Then, if the first steps of the commissioning have returned a positive evaluation, the performance of the CPV plant is assessed through an on-site measurement campaign. The conclusions of the CPA need to be representative of the overall capacity of the CPV project to generate electrical energy. Nevertheless, accurate measurements are only achievable under a limited range of operating conditions. To reach this objective, we suggest that the measurements to be performed during a specific period of time $T$ should be considered valid only if the following conditions are satisfied:

(1) $T$ is longer than 5 days.

(2) The accumulated DNI received by the CPV system during $T$ is larger than $15 \mathrm{kWh} / \mathrm{m}^{2}$.

(3) The operating conditions during $T$ verify that:

$E_{R E F}^{T, \theta} \geqslant 0.80 E_{R E F}^{T, \Omega}$

where $E_{R E F}^{T, \Omega}$ is the energy that the reference system would produce during the entire period; $E_{R E F}^{T, \theta}$ is the energy that the reference system would produce during the particular moments that satisfy, as explained below, the following operating conditions: no shading, no soiling, absolute Air Mass $(A M)<3, \mathrm{DNI}>600 \mathrm{~W} / \mathrm{m}^{2}, T_{a}>15^{\circ} \mathrm{C}$, and $W_{s}<10 \mathrm{~W} / \mathrm{m}^{2}$.

The rationale behind the 0.80 factor in Eq. (23) is that, if the uncertainty of the measurements rises up to $10 \%$ during the moments corresponding to $20 \%$ of the energy production of the CPV system, the maximum added uncertainty introduced in the estimation of its global energy yield is still only $0.10 \times 0.20=2 \%$.

The accurate characterization of a CPV project requires that the CPV modules be free of shading, and ideally free of soiling. At least, the levels of dirt on the CPV modules and on the pyrheliometer need to be both low and similar. $A M$ must be less than 3 to avoid excessive current mismatch in III-V cells, where $A M$ is defined as follows:

$A M=\frac{1}{\cos \left(\theta_{z}\right)} \times e^{-0.0001184 h}$

where $\theta_{z}$ is the Sun's zenith angle and $h$ is the elevation of the location (in $\mathrm{m}$ ). As a representative case, Fig. 4 shows that for the majority of sites where CPV systems are installed or projected, more than $90 \%$ of the annual energy production corresponds to $A M$ values less than 3. 
Note also that the conventional AM1.5 figure used for STC reporting roughly corresponds to the median value of DNI. Moreover, DNI must be greater than $600 \mathrm{~W} / \mathrm{m}^{2}$ to avoid second-order effects related to circumsolar irradiance [82], and non-linear threshold effects in the CPV system. Under low AOD conditions $(\beta<0.10)$, which usually occur over regions where the installation of CPV systems makes the most sense, the condition $D N I>600 \mathrm{~W} / \mathrm{m}^{2}$ is roughly equivalent to $A M<3 . T_{a}$ must be greater than $15^{\circ} \mathrm{C}$, because the impact of lower temperatures on the optical elements tends to increase the area of the light spot on the cells [83]. $W_{s}$ must be less than $10 \mathrm{~m} / \mathrm{s}$, because under higher wind speeds, air turbulence makes it very difficult to estimate the heat transfer between the CPV modules and air, and because some trackers lose accuracy $[84,85]$. Fig. 5 shows the extreme case of a CPV system in Spain whose power decreases drastically for wind speeds larger than $5 \mathrm{~m} / \mathrm{s}$.

This CPV system is made up of a tracker whose receiving area is $\approx 250 \mathrm{~m}^{2}$. As a consequence, the distribution of air pressure is not uniform on its surface, and the wind causes it to swing, which displaces the light spots to outside the cell area during significant periods. The same trackers equip the Spanish 12-MW CPV plant already mentioned above, and whose performance has been reported to be well below par. This type of system would not directly qualify as acceptable for $\mathrm{CPA}$, even before performing the precise evaluation of its energetic performance. However, restricting the analyses to $W_{s}<10 \mathrm{~m} / \mathrm{s}$ is an important precaution to be applied to all measurements. If all these restrictions are applied, the measurements will still represent more than $80 \%$ of the operating conditions at the majority of locations that are suitable for CPV systems. At some locations, these restrictions could exclude on-site measurement campaigns during periods that are close to the winter solstice. Such periods should be avoided if possible.

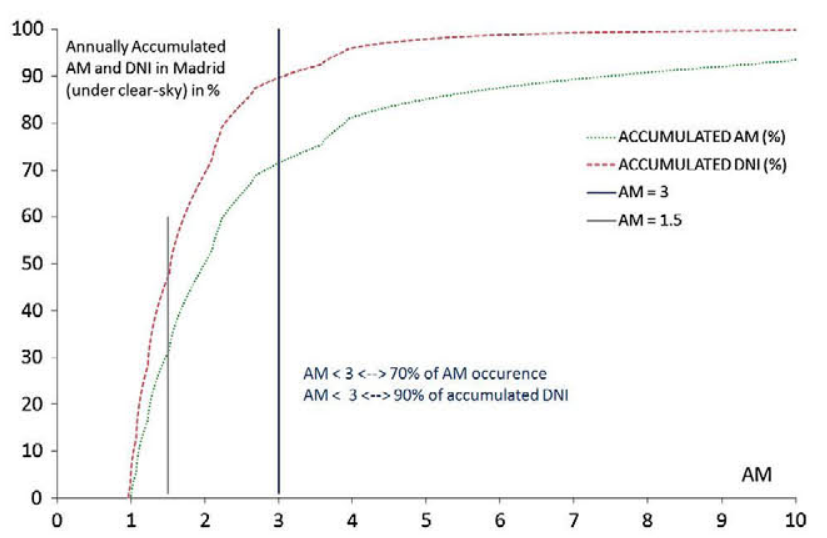

Fig. 4. Accumulated distribution of $A M$ and DNI under clear-sky conditions in Madrid during 2011.

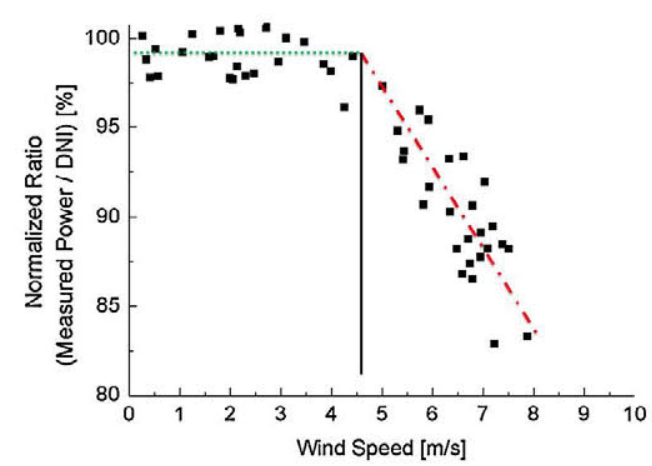

Fig. 5. Power decrease for wind speeds higher than $5 \mathrm{~m} / \mathrm{s}$ observed on a CPV system in northern Spain.
At the end of the measurement campaign, the measured energy production ( $E_{\text {MEAS }}$ ) is compared to the target energy production ( $E_{\text {TARGET }}=E_{\text {REF }} \times P_{\text {TARGET }}$ ) of the CPV project, as estimated from the physical model described above. Its inputs are obtained from the in situ weather conditions, and from the baseline loss scenario associated with $P I_{\text {TARGET }}$. The relationship between target and measurements then permits an adjustment parameter, $a_{C P A}$, to be defined, such that:

$a_{\text {CPA }}=\frac{E_{\text {MEAS }}}{E_{\text {TARGET }}}=\frac{\int_{T} P_{\text {MEAS }} d t}{\int_{T} P_{\text {TARGET }} d t}$

The Performance Index estimated as a result of CPA can then be defined as:

$P I_{C P A}=P I_{\text {TARGET }} \times a_{C P A}$

The CPV project is rejected if $P I_{C P A}$ is less than $P I_{\text {TARGET }}$ (or if $a_{C P A}<1$, which is equivalent).

\section{Certificate of Final Acceptance (CFA)}

The Certificate of Final Acceptance (CFA) is ideally carried out 1 or 2 years after the commissioning of the CPV project on the basis of the operational data monitored in situ. Its main objectives are to evaluate the quality of the operation and maintenance procedures, to detect hidden problems that would have passed undetected during the previous step (CPA), and to evaluate the impact of some second-order effects that could affect the long-term energy production of the project, such as the accumulation of dirt on the modules, occasional or rare failure issues, or early signs of degradation or aging [86,87] of certain components. A good monitoring system combined with good procedures to automatically analyze the data allows for in-depth detection and diagnosis of failures, which in turn helps mitigate their energetic impact by a prompt and adequate intervention when necessary. Good monitoring procedures also allow for independent and automatic reporting of the performance of the CPV plant over time, which is of great help to financial investors. We argue that the losses resulting from soiling on the CPV modules are still largely ignored or underestimated [88]. Dirt attenuates the direct much more than the global irradiance, but little has been published on this issue for the particular case of CPV. Furthermore, CPV projects are generally envisioned in dry, harsh climates, where the accumulation of dust on the modules could be significant. The relationship between target and measurements can be used to define an adjustment parameter:

$a_{\text {CFA }}=\frac{E_{\text {MEAS }}}{E_{\text {TARGET }}}$

The real Performance Index can then be estimated more precisely as follows:

$P I_{\text {CFA }}=P I_{\text {TARGET }} \times a_{\text {CFA }}$

The CPV project is rejected if $P I_{\text {CFA }}$ is less than the $P I_{\text {TARGET }}$ (or if $a_{C F A}<1$, which is equivalent).

\section{Conclusions and discussion}

In this contribution we propose a four-step methodology to assess the performance of a CPV project through on-site measurements and ultimately ensure its bankability. This procedure can be used to conduct a bankability assessment of a CPV plant that uses any kind of technology currently available on the market (including cells with more than 3 junctions), and that operates under the whole range of climatic conditions suitable for its installation. It is designed to be fully compliant with international 
standards and to be easily combined with local regulations. In consequence, its applicability is both general and international.

First, a Solar Resource Assessment (SRA) is carried out before the construction phase. This method, if conducted under the current best practice, should guarantee an uncertainty in the estimation of the long-term average of the annual solar resource of $\approx 3 \%$, under the hypothesis that no major climatic event modifies the atmospheric aerosol content, such as major volcanic eruptions, and that no long-term trends produce strong departure from the historical trend, due to e.g., climate change.

In a second step, a Yield Assessment (YA) is carried out on the basis of the results of the SRA and the technical information provided by the EPCC. At this stage, the EPCC provides all the necessary technical information concerning the projected CPV plant. This information is extracted from the datasheets provided by the manufacturers of the components, the construction project plans, and the compliance with both international standards and applicable local regulations. The Yield Assessment is carried out using a physical model to simulate the energetic yield of a reference CPV system. Its technical characteristics are extracted directly from the technical information supplied by the EPCC. This means that its performance is assumed to be optimal, and all its components are assumed to correspond exactly to the technical datasheets of the manufacturers. Then, as the real CPV plant will generally perform below the reference CPV system, a margin of safety is provided by establishing a Performance Index (PI) that is less than unity, and that is used as a realistic target $\left(P_{\text {TARGET }}\right)$.

Third, once the project is commissioned, an on-site measurement campaign is carried out and its fulfillment leads to the awarding of the Certificate of Provisional Acceptance (CPA). Before measuring the actual performance of a PV plant, it is necessary to verify that the project has been properly executed. Therefore, at first, a commissioning procedure is undertaken to verify the proper installation and functioning of the CPV plant. This includes visual inspections, electrical and thermographic measurements, verification of the completeness and consistency of the as-built documentation, and compliance with local regulations.

Finally, 1 or 2 years after commissioning, the data monitored on-site are used to further scrutinize the installation's real performance. If fulfilled satisfactorily, a Certificate of Final Acceptance (CFA) is awarded. Its main objectives are to evaluate the quality of the operation and maintenance procedures, to detect hidden problems that would have passed undetected during the CPA, and to evaluate the impact of possible second-order effects that could affect the energy production of the CPV project.

This methodology allows the long-term energy production of a CPV project to be estimated with an associated uncertainty of $\approx 5 \%$, which translates into an $E_{P 90}$ value that is typically $6.5 \%$ lower than $E_{P 50}$. The $E_{P 90}$ approach alone is not suitable to assess certain kinds of risks whose probability of occurrence or magnitude does not follow a Gaussian distribution. This is the case of events characterized by both a low probability of occurrence and a high impact in case of occurrence, e.g., major natural disasters or volcanic eruptions. This is also the case for the risks related to the non-compliance to mandatory international standards or local regulation, which do not show up through the analysis of the performance of the CPV plant, but which can bear critical consequences on the economic viability of the project. Some of these risks can be minimized through due diligence, both at technical and legal levels, during several critical steps of the project. Some other risks are better mitigated through a specific insurance policy.

\section{Acknowledgments}

The authors thank and congratulate Rubén Nuñez for his excellent job at operating and maintaining the meteorological station of
IES-UPM. We were fortunate to benefit from the proofreading and comments of Catherine Praile and Loreto González Bonilla. This work has been partially supported by the European Commission within the project PV CROPS [89] (Photovoltaic Cost reduction, Reliability, Operational performance, Prediction and Simulation) under the 7th Framework Program (Grant Agreement no. 308468).

\section{References}

[1] EnergyTrend (<http://www.energytrend.com>).

[2] Hegedus S, Luque A. Handbook of photovoltaic science and engineering, achievements and challenges of solar electricity from photovoltaics. Wiley; 2012 [Chapter 1].

[3] Merkle EW, Tölle R, Sturm M. High-efficient low-cost photovoltaics: recent developments, the economic perspective: is concentrator PV capable of breaking the economic barrier. Springer; 2012 [Chapter 9].

[4] CPV consortium (<http://www.cpvconsortium.org $>$ ).

[5] Kurtz S. Opportunities and challenges for development of a mature concentrating photovoltaic power industry, challenges and opportunities. In: Technical, Report NREL/TP-5200-43208; 2011.

[6] Menoufi K, Chemisana D, Rosell JI. Life cycle assessment of a building integrated concentrated photovoltaic scheme. Appl Energy 2013;111:505-14. ISSN 0306-2619.

17] Orioli A, Di Gangi A. Review of the energy and economic parameters involved in the effectiveness of grid-connected PV systems installed in multi-storey buildings. Appl Energy 2014;113:955-69. ISSN 0306-2619.

[8] Hampl N, Lüdeke-Freund F, Flink C, Olbert S, Ade V. In: Goetzpartners, and Colexon, editors. The myth of bankability - definition and management in the context of photovoltaic project financing in Germany; 2011.

[9] Trujillo Serrano PJ, Alamillo Davila C, Martínez Montes M, de la Rubia O, Rubio F, Masa-Bote D, et al. Instituto de Sistemas Fotovoltaicos de Concentración concentration photovoltaics hybrid system first year of operation and improvements. Prog Photovolt: Res Appl 2013;21:1260-75. http://dx.doi.org/ $10.1002 /$ pip 236 .

[10] Kinsey GS, Stone K, Brown J, Garboushian V. Energy prediction of Amonix CPV solar power plants. Prog Photovolt: Res Appl 2011;19:794-6. http:/ dx.doi.org/10.1002/pip.1037.

[11] Verlinden P, Lasich J. Analysis and simulation of performance of CPV systems with multi-junction solar cells. AIP Conf Proc 2010;1277:277. http:/I dx.doi.org/10.1063/1.3509210.

[12] Antonini A, Butturi MA, Di Benedetto P, Uderzo D, Zurru P, Milan E, et al. Rondine ${ }^{8}$ PV concentrators: field results and developments. Prog Photovolt: Res Appl 2009;17:451-9. http://dx.doi.org/10.1002/pip.907.

[13] IEC 62670-1. Concentrator photovoltaic (CPV) module and assembly performance testing and energy rating - Part 1: performance measurements and power rating - irradiance and temperature.

[14] ASTM E2527-09. Standard test method for electrical performance of concentrator terrestrial photovoltaic modules and systems under natural sunlight.

[15] Kurtz S, Muller M, Marion B, Emery K, McConnell R, Surendran S, et al. Considerations for how to rate CPV. University of Nevada, Publications (E), Paper $41 ; 2011$.

[16] Vivar M, Clarke M, Pye J, Everett V. A review of standards for hybrid CPVthermal systems. Renew Sustain Energy Rev 2012;16(1):443-8. ISSN 13640321, 10.1016/j.rser.2011.08.008, 2012.

[17] Pérez-Higueras P, Muñoz E, Almonacid G, Vidal PG. High concentrator photovoltaics efficiencies: present status and forecast. Renew Sustain Energy Rev 2011;15(4):1810-5. ISSN 1364-0321, 10.1016/j.rser.2010.11.046.

[18] Emery K, Meusel M, Beckert R, Dimroth F, Bett A, Warta W. Procedures for evaluating multijunction concentrators. In: Photovoltaic specialists conference. Conference record of the twenty-eighth IEEE, vol., no.; 2000. p. 1126-30. doi: 10.1109/PVSC.2000.916085.

[19] Muñoz E, Vidal PG, Nofuentes G, Hontoria L, Pérez-Higueras P, Terrados J, et al. CPV standardization: an overview. Renew Sustain Energy Rev 2010;14(1):518-23. ISSN 1364-0321, <http://www.dx.doi.org/10.1016/ j.rser.2009.07.030>

[20] Sala G, Antón 1. Handbook of photovoltaic science and engineering, photovoltaic concentrators. Wiley; 2012 [Chapter 10].

[21] Almonacid F, Fernández EF, Rodrigo P, Pérez-Higueras PJ, Rus-Casas C. Estimating the maximum power of a High Concentrator Photovoltaic (HCPV) module using an artificial neural network. Energy 2013;53:165-72. ISSN 0360-5442, doi:10.1016/j.energy.2013.02.024

[22] REN21. In: Renewable Global Status Report; 2013. p. 47.

[23] Gupta R. CPV - expansion and bankability required. Renew Energy Focus 2013.

[24] Lorenzo E. Retratos de la conexión fotovoltaica a la red. (XVIII), De moratorias, creencias, adivinanzas y algún suceso feliz. Era Solar no. 167; 2012.

[25] Caamaño E, Lorenzo E, Zilles R. Quality control of wide collections of PV modules: lessons learned from the IES experience. Prog Photovolt: Res Appl $1999 ; 7: 137-49$. PIP249>3.0.CO;2-C

[26] Martínez-Moreno F, Lorenzo E, Muñoz J, Moretón R. On the testing of large PV arrays. Prog Photovolt: Res Appl 2012;20:100-5. http://dx.doi.org/10.1002/ pip. 1102 . 
[27] Muñoz J, Martínez-Moreno F, Lorenzo E. On-site characterisation and energy efficiency of grid-connected PV inverters. Prog Photovolt: Res Appl 2011;19:192-201. http://dx.doi.org/10.1002/pip.997.

[28] García M, Marroyo L, Lorenzo E, Pérez M. Soiling and other optical losses in solar-tracking PV plants in Navarra. Prog Photovolt: Res Appl 2011;19:211-7. http://dx.doi.org/10.1002/pip.1004.

[29] Muñoz J, Lorenzo E, Martínez-Moreno F, Marroyo L, García M. An investigation into hot-spots in two large grid-connected PV plants. Prog Photovolt: Res Appl 2008;16:693-701. http://dx.doi.org/10.1002/pip.844.

[30] Fernández EF, Pérez-Higueras P, Garcia Loureiro AJ, Vidal PG. Outdoor evaluation of concentrator photovoltaic systems modules from different manufacturers: first results and steps. Prog Photovolt: Res Appl 2012. http:/ dx.doi.org/10.1002/pip.126.

[31] Nofuentes G, Aguilera J, Santiago RL, de la Casa J, Hontoria L. A referencemodule-based procedure for outdoor estimation of crystalline silicon PV module peak power. Prog Photovolt: Res Appl 2006;14:77-87. http:/ dx.doi.org/10.1002/pip.636.

[32] Muñoz JV, Nofuentes G, Aguilera J, Fuentes M, Vidal PG. Procedure to carry out quality checks in photovoltaic grid-connected systems: six cases of study. Appl Energy 2011;88(8):2863-70. ISSN 0306-2619.

[33] Leloux J, Pachon D, Sala G. Spectral solar radiation measurements and models for CPV module production estimation. In: 6 th International conference on concentrating photovoltaic systems: CPV-6, 1277, 329; 2010. doi:10.1063 1.3509223 .

[34] García B, Aguilera J, Fuentes M, Muñoz JV, Nofuentes G. Analysis and characterization of an outdoor CPV system. Comparative with other PV technologies, 26th EUPVSEC; 2011.

[35] Moody's investor service, PV Solar Power Generation Projects; 2010.

[36] Reda I. In: Method to calculate uncertainties in measuring shortwave solar irradiance using thermopile and semiconductor solar radiometers (technical report no. NREL/TP-3B10-52194), National Renewable Energy Laboratory (NREL); 2011.

[37] Leloux J, Narvarte I. Trebosc D. Review of the performance of residential PV systems in Belgium. Renew Sustain Energy Rev 2012;16(1):178-84. ISSN $1364-0321$

[38] Leloux J, Narvarte L, Trebosc D. Review of the performance of residential PV systems in France. Renew Sustain Energy Rev 2012;16(2):1369-76. ISSN 1364-0321.

[39] Barry B. Errors in practical measurement in science, engineering, and technology, propagation of errors in computing. Wiley; 1978 [Chapter 7].

[40] SoDa (<http://www.soda-is.com>).

[41] IrSOLaV (<http://irsolav.com>)

[42] SolarGIS (<http://www.solargis.info>)

[43] Erbs DG, Klein SA, Duffie JA. Estimation of the diffuse radiation fraction for hourly, daily and monthly-average global radiation. Sol Energy 1982;28(4):293-302. ISSN 0038-092X, doi:10.1016/0038-092X(82)90302-4..

[44] Liu B, Jordan RC. The interrelationship and characteristic distribution of direct, diffuse, and total solar radiation. Sol Energy 1960;4:1-9.

[45] Hay JE. Calculating solar radiation for inclined surfaces: practical approaches. Renew Energy 1993;3(4-5):373-80. ISSN 0960-1481, doi:10.1016/09601481(93)90104-0.

[46] Rodrigo P, Pérez-Higueras PJ, Almonacid F, Hontoria L, Fernández EF, Rus C. Calculation of direct normal irradiation from global horizontal irradiation. In: 8th International conference on concentrating photovoltaic systems: CPV-8, 1477, 391; 2012. doi:10.1063/1.4753912.

[47] Gueymard CA. SMARTS, A simple model of the atmospheric radiative transfer of sunshine: algorithms and performance assessment. In: Technical report no. FSEC-PF-270-95, Florida Solar Energy Center, Cocoa, FL; 1995.

[48] Gueymard CA, Gustafson WT, Bender G, Etringer A, Storck P. Evaluation of procedures to improve solar resource assessments: optimum use of shortterm data from a local weather station to correct bias in long-term satellite derived solar radiation time series. Denver, CO: World Renewable Energy Forum; 2012.

[49] Gueymard CA. Temporal variability in direct and global irradiance at various time scales as affected by aerosols. Sol Energy 2012. http://dx.doi.org/10.1016/ i.solener.2012.01.013.

[50] Aeronet (<http://www.aeronet.gsfc.nasa.gov>).

[51] Gueymard CA. Uncertainties in modeled direct irradiance around the sahara as affected by aerosols: are current datasets of bankable quality? J Sol Energy Eng 2011;133(3):031024-031024-13. http://dx.doi.org/10.1115/1.400438.

[52] Stoffel T, Renné D, Myers D, Wilcox S, Sengupta M, George R. et al. Concentrating solar power, best practices handbook for the collection and use of solar resource data. In: Technical report NREL/TP-550-47465; 2010.

[53] Schumann K, Beyer HG, Chhatbar K, Meyer R. Improving satellite-derived solar resource analysis with parallel ground-based measurements. In: ISES Solar World Congress; 2011.

[54] Schnitzer M, Thuman C, Johnson P. The impact of solar uncertainty on project financeability: mitigating energy risk through on-site monitoring, World renewable energy forum. Am Sol Energy Soc 2012.

[55] Latha R, Murthy BS, Kumar M, Jyotsna S, Lipi K, Pandithurai G, et al. Aerosol optical properties and composition over a table top complex mining area in the monsoon trough region. Aerosol Air Qual Res 2013. http://dx.doi.org/ 10.4209/aaqr.2013.02.0062.

[56] Red de Energía Solar Fotovoltaica de Latinoamérica y el Caribe (<http:// www.redsollac.org>)
[57] Gueymard CA. REST2: high-performance solar radiation model for cloudlesssky irradiance, illuminance, and photosynthetically active radiation validation with a benchmark dataset. Sol Energy 2008;82:272-85.

[58] Gueymard CA, Kambezidis H. Solar radiation and daylight. In: Muneer T, editor. Solar spectral radiation. Elsevier; 2004 [Chapter 5].

[59] World Meteorological Organization, IAMAP. A preliminary cloudless standard atmosphere for radiation computation. In: Rep. WCP-112, WMO/TD-No. 24 1986.

[60] Gueymard CA. Turbidity determination from broadband irradiance measurements: a detailed multicoefficient approach. J Appl Meteorol 1998;37:414-35.

[61] Gueymard CA. Aerosol turbidity derivation from broadband irradiance measurements: methodological advances and uncertainty analysis. In: ASES solar 2013 conference; 2013.

[62] Pons A, Corróns A. Solar irradiance spectrum at Madrid. Atmos Environ 1981;16(9):2237-40. ISSN 0004-6981, $10.1016 / 0004$ 6981(82)90293-1.

[63] Wild $\mathrm{M}$ et al. Global dimming and brightening: an update beyond 2000 . J Geophys Res 2009;114:D00D13. http://dx.doi.org/10.1029/2008JD01138.

[64] Wild $M$ et al. Global dimming and brightening: a review. J Geophys Res 2009;114:D00D16. http://dx.doi.org/10.1029/2008JD011470.

[65] ISO/IEC, ISO/IEC Guide 98-3:2008. Uncertainty of measurement -Part 3: guide to the expression of uncertainty in measurement; 2008.

[66] Thevenard D, Pelland S. Estimating the uncertainty in long-term photovoltaic yield predictions. Sol Energy 2013;91:432-45. ISSN 0038-092X, <http:/ www.dx.doi.org/10.1016/j.solener.2011.05.006>.

[67] Goy S, Tjengdrawira C, Gheysen T, Irissou A, Ortega S, Morilla Padial C. How to mitigate risks in PV projects: lessons learned worldwide in manufacturing, commissioning and operation of PV power plants. In: 28th European photovoltaic solar energy conference; 2013.

[68] Peharz G, Ferrer Rodríguez JP, Siefer G, Bett AW. Investigations on the temperature dependence of CPV modules equipped with triple-junction solar cells. Prog Photovolt: Res Appl 2011;19:54-60. http://dx.doi.org/10.1002 pip.98.

[69] Fernández EF, Almonacid F, Rodrigo P, Pérez-Higueras P. Calculation of the cel temperature of a high concentrator photovoltaic (HCPV) module: a study and comparison of different methods. Sol Energy Mater Sol Cells 2014;121:144-51. http://dx.doi.org/10.1016/i.solmat.2013.11.00. ISSN 09270248 .

[70] Gordon JM. Concentrator photovoltaics, concentrator optics. Springer; 2007 [Chapter 6].

[71] Martínez M. Wind velocity and tracking accuracy for CPV. In: 8 th Internationa conference on concentrating photovoltaic systems: CPV-8; 2012.

[72] Bett AW et al. Concentrator photovoltaics, multijunction concentrator solar cells. Springer; 2007 [Chapter 4].

[73] Peharz G, Siefer G, Bett AW. A simple method for quantifying spectral impacts on multi-junction solar cells. Sol Energy 2009;83(9):1588-98. http:/ dx.doi.org/10.1016/j.solener.2009.05.00. ISSN 0038-092X.

[74] Nishioka K, Takamoto T, Agui T, Kaneiwa M, Uraoka Y, Fuyuki T. Annual output estimation of concentrator photovoltaic systems using high-efficiency InGaP/ InGaAs/Ge triple-junction solar cells based on experimental solar cell's characteristics and field-test meteorological data. Sol Energy Mater Sol Cells 2006;90(1):57-67. http://dx.doi.org/10.1016/i.solmat.2005.01.011. ISSN 0927-0248.

[75] Gerstmaier T, Van Riesen S, Gombert A, Mermoud A, Lejeune T, Duminil E. Software modeling of FLATCON CPV systems. In: AIP conference proceedings, vol. 1277, issue $1 ; 2010$. p. 183.

[76] Leloux J. Measurement and simulation of spectral solar radiation for CPV modules production estimation. Diploma de Estudios Avanzados (DEA), Universidad Politécnica de Madrid; 2010.

[77] Antón I, Martínez M, Rubio F, Núñez R, Herrero R, Domínguez C, et al. Power rating of CPV systems based on spectrally corrected DNI. In: 8th Internationa conference on concentrating photovoltaic systems: CPV-8, 1477, 331; 2012 . doi: $10.1063 / 1.4753898$

[78] Victoria M, Askins S, Nuñez R, Domínguez C, Herrero R, Antón I, et al. Tuning the current ratio of a CPV system to maximize the energy harvesting in a particular location. In: 8th International conference on concentrating photovoltaic systems: CPV-8, 1556, 156; 2012, doi: $10.1063 / 1.4822221$.

[79] Fraunhofer Institute for Solar Energy Systems ISE, Soitec, CEA Leti, World Record Solar Cell with 44.7\% Efficiency, Press Release, No. 22/13; $2013 ;$ p. 1.

[80] Luque A. Will we exceed 50\% efficiency in photovoltaics? J Appl Phys 2011;110:031301. http://dx.doi.org/10.1063/1.3600702.

[81] Perpiñán O. Cost of energy and mutual shadows in a two-axis tracking PV system. Renew Energy 2011; doi:10.1016/j.renene.2011.12.001.

[82] Gueymard CA. Spectral circumsolar radiation contribution to CPV. In: 6th International conference on concentrating photovoltaic systems: CPV-6, AIP Conf. Proc. 1277; 2010.

[83] Leutz R, Suzuki A. Nonimaging fresnel lenses: design and performance of solar concentrators, lens evaluation. Springer; 2001 [Chapter 6].

[84] Davis M, Williams T, Martínez M, Sanchéz D. Understanding tracker accuracy and its effects on CPV. In: 5 th International conference on solar concentrators, Palm Desert, CA; 2008.

[85] Pfahl A, Buselmeier M, Zaschke M. Wind loads on heliostats and photovoltaic trackers of various aspect ratios. Sol Energy 2011;85(9):2185-201. ISSN 0038092X, 10.1016/j.solener.2011.06.006. 
[86] Vázquez M, Algora C, Rey-Stolle I, González JR. III-V concentrator solar cel reliability prediction based on quantitative LED reliability data. Prog Photovolt: Res Appl 2007;15(9):477-91. http://dx.doi.org/10.1002/pip.753.

[87] Vázquez M, Rey-Stolle I. Photovoltaic module reliability model based on field degradation studies. Prog Photovolt: Res Appl 2008;16:419-33. http:// dx.doi.org/10.1002/pip.825.
[88] Vivar M, Herrero R, Antón I, Martínez-Moreno F, Moretón R, Sala G, et al. Effect of soiling in CPV systems. Sol Energy 2010;84(7):1327-35. http://dx.doi.org/ 10.1016/j.solener.2010.03.03. ISSN 0038-092X.

[89] PV CROPS (Photovoltaic Cost r€duction, Reliability, Operational performance, Prediction and Simulation), European Commission FP7 project (<http:/ www.pvcrops.eu/>). 